\title{
Organisational development in healthcare: approaches, innovations, achievements
}

\author{
Edited by E. Peck \\ Radcliffe Publishing Ltd., UK, 2005, pp 305, \\ ISBN 185775896 X
}

This book explores and describes Organisational Development (OD), in the context of the British NHS, addressing NHS-managers and clinicians, students of leadership, management and change and those involved in OD in public services. According to the editor, OD appears to be very popular among NHS managers and practitioners, especially while it is their perception that it can support the local implementation of national policy.

The book consists of three parts. The first (introductory) part (Ch 1-4) focuses on the conceptualisation of OD. The second part (Ch 5-12) gives an overview of various approaches or "schools", presenting different views and models of OD. The last part (Ch 13) looks at the evidence of OD in health care. These parts are 'surrounded' by an Introduction and Conclusion of the editor, which clarify the intentions of the book and the limitations of the different approaches respectively. The book intends to be more than, as the editor says, "a simple cook book of tools and techniques: it has a theoretical dimension, so that the book can serve as an introduction to organisational theory as well as to organisational development".

To counterbalance the pantheistic version of OD, saying that anything done to improve the organisation is OD, the first chapter aims to identify the distinct nature of $\mathrm{OD}$, identified as "the overarching aim of not only improving organisational performance but also creating a continually reflexive and learning organisation". This view shows the way to theories of organisational learning, sense-making, action research, images of organisations and whole systems thinking. Chapter 2 elaborates on the question how OD can support successful policy implementation in health care organisations, often viewed as a matter of finding the balance between adoption (as desired by policymakers) and adaptation (as desired by stakeholders) of policy decisions and measures. The focus of chapter 3 is on leadership, pointing out that the so-called repertoire approachwhich means that good leaders have a high ability to tune their responses to the context in which they operate-provides a robust conceptual underpinning of leadership as a major tool of OD. Chapter 4 presents and discusses the OD cycle of contract and entry, data collection, data analysis, data feedback and negotiating the interventions, taking actions (implementing the interventions) and evaluation.

Chapters 5-12 are more or less equally structured (with theoretical notions, tools and techniques, comments/limitations/critique and conclusion) and discuss the following topics:

- $\quad$ service improvement, presented as a core feature of the NHS Modernisation Agency and comprising a variety of tools to improve patient services

- psychodynamic approaches, based on the study of mental forces, operating in inter-active situations and influencing individual thinking and behaviour. Central to the author's approach is the aim to facilitate collaboration, by fostering a culture of curiosity and inquiry instead of a culture of blame

- systems theories and their applications, exploring the core features of systems theory and its relation to e.g. the learning organisation and knowledge management

- emergence and complexity, which discusses the question how to deal with the current complexity, which is connected to unpredictability of steakholders' responses and the uncertainties in health care organisations

- structure, addressing the NHS structural reforms as a political response to what was considered the failing performance of the NHS.

- culture, looking at how to use notions on culture to develop organisations and to arrive at organisational change

- critical appreciative inquiry, which is an action research method and a prevalent consultancy methodology discourse for working with OD, fitting within a social constructionist framework. The central feature is an approach, putting forward the obligation to create positive talk, spirit, energy and the emotions of joy and pride

- $\quad$ narrative and story telling in OD, investigating the place and impact of storytelling in OD in health and social care.

The final chapter, addressing organisational development in health care, tries to connect OD to the (especially British) health care setting, outlining the current available health care-related impact of OD by reviewing the evidence on outcomes of service 
improvement initiatives. In this context it draws attention for the impact of special health care characteristics, such as the dominant role of (medical) professionals.

The topic of OD is relevant for those involved in integrated care (IC), as IC development and implementation is often a major change process. Whereas in the case of IC it is about cooperation and thus dealing with complexity, the need of flexibility, the fostering of innovation mindedness and a culture of trust, respect and critical examination, several OD approaches described here, such as psychodynamics, the emergent and complexity approach, critical appreciative inquiry and service improvement and assessment are interesting for IC managers and workers. But does the book also contribute to their innovative capacities and skills? On the one hand, the answer might be yes, while the book demonstrates-although mostly in a general and often abstract manner-OD tools and techniques and explains why OD is complicated and difficult. On the other hand, the book does not succeed to clarify more precisely what are the special characteristics of the health care sector in relation to what this means for OD, for example in terms of threats and opportunities. With a few exceptions, especially in the last chapter that e.g. discusses what the professionals' resistance to the call of integration and change means to OD work, the approaches demonstrate a lack of health care related notions and analysis.

Second, at first glance, the book looks very British and thus maybe less relevant for other countries, as it tries to place OD in the context of the NHS, also reflecting typical British ideas about health care governance. A, for instance, Dutch healthcare manager or clinician, not living under the Beveridge regime, would never ever consider his or her policy and actions as the implementation of governmental policy. When looking at the other intention of the book, however, i.e. to be an introduction to organisational theory and OD, it has a wider meaning. It provides the reader with short introductory overviews of concepts, models and theories from organisational science. These overviews may be interesting for those familiar with organisational theory, especially to recognize and remember (part of) the broad theoretical variety in this area and to receive notice of recent developments. But the overviews are often too short and sometimes too superficial for starting students to acquire deeper theoretical insights. They can only serve as a starting point for further search, which could be, by the way, also an important function of the book. The extensive lists of references (books, articles and websites) with classical and recent literature are very valuable in this respect.

Finally, from an academic point of view, it is to be appreciated that the authors demonstrate a critical attitude to their own work and that of others. They critically discuss the different theories and approaches and mention limitations of theories and their applications, such as political manipulation and abuse of approaches.

The final conclusion is that this book, being a balanced mix of theory and experience, is interesting and worthwhile for the variety of readers as mentioned by the editor, as long as people from practice do not expect ready recipes for OD action and students and scientists do not search for extended descriptions and in-depth discussions of conceptual frameworks and theoretical approaches.

Ingrid Mur-Veeman, $\mathrm{PhD}$, University of Maastricht 